\title{
Smile esthetics: Impact of variations in the vertical and horizontal dimensions of the maxillary lateral incisors
}

\author{
Amjad Al Taki ${ }^{1}$, Ahmad Mohammad Hamdan², Ziad Mustafa ${ }^{3}$, \\ Mawada Hassan ${ }^{3}$, Sami Abu-Alhuda ${ }^{1}$
}

Correspondence: Dr. Amjad Al Taki Email: al_taki@hotmail.com

\begin{abstract}
'Smile Spa Dental Clinic, Private Practice, Dubai, UAE, 2Department of Orthodontic and Pediatric Dentistry, Faculty of Dentistry, University of Jordan, Amman, Jordan,

${ }^{3}$ Department of Clinical Dentistry, College of Dentistry, Ajman University of Science and Technology, Ajman, UAE
\end{abstract}

\section{ABSTRACT}

Objective: The purpose of this study was to determine the perception of trained dental professionals and laypersons toward the esthetic impact of variations in the vertical position, width, and gingival height of the maxillary lateral incisor. Materials and Methods: The present study analyzed the perspective of smile photographs by dental professionals such as "fifty orthodontics and fifty general dental practitioners (GDPs)" as well as fifty laypersons, consisting of an equal number of male and female participants. Photographs edited to depict alteration of golden proportion, incisal length, and gingival height of lateral incisor. SPSS software was used to analyze the data and determine the significant difference within all the participants, at $0.05 \%$ level (95\% confidence interval). Results: There was no significant difference in ranking between the genders. Golden proportion of $62 \%-67 \%$ were ranked the highest by orthodontists, whereas GDPs and laypersons preferred $67 \%$. Regarding gingival display, corrected height of -0.5 and $-1 \mathrm{~mm}$ received highest ranking from all the three groups. In case of lateral incisal length, $-0.5 \mathrm{~mm}$ was ranked highest by laypersons, in contrast to $-1 \mathrm{~mm}$ by orthodontists and GDPs. Conclusion: Specific differences were observed in the ranking of smile esthetics by health-care professionals and laypersons. Golden proportion of $62 \%$ and $67 \%$ were ranked the highest by orthodontists, whereas GDPs and laypersons preferred $67 \%$. Corrected gingival height of -0.5 and $-1 \mathrm{~mm}$ received highest ranking from all the three groups. In case of lateral incisal length, $-0.5 \mathrm{~mm}$ was ranked highest by laypersons, in contrast to $-1 \mathrm{~mm}$ by orthodontists and GDPs.

Key words: Gingival height, golden proportion, incisal length, lateral incisor, smile aesthetics

\section{INTRODUCTION}

Attractive anterior teeth with proper size and shape were one of the most influential factors contributing to a pleasant smile in most of the dental health-care professionals such as orthodontic, operative, and prosthodontic management. ${ }^{[1]}$

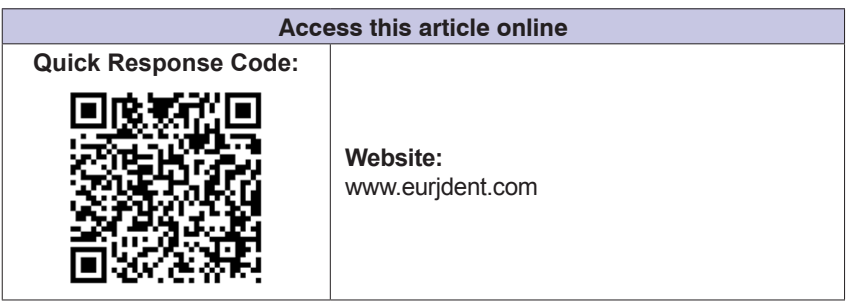

Design of esthetic smile is a complex process that requires a multidisciplinary approach. Popularity of designing a natural attractive smile as an architectural

This is an open access article distributed under the terms of the Creative Commons Attribution-NonCommercial-ShareAlike 3.0 License, which allows others to remix, tweak, and build upon the work non-commercially, as long as the author is credited and the new creations are licensed under the identical terms.

For reprints contact: reprints@medknow.com

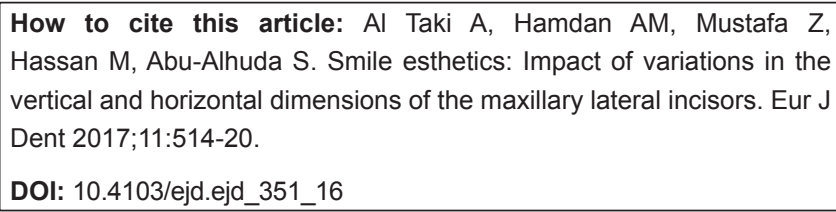


blueprint used in esthetic dentistry has risen to achieve optimal esthetic results. ${ }^{[2,3]}$

One of the most important aspects of dental and facial esthetics is vertical anterior tooth display. Consequently, dental and gingival display and asymmetries must be carefully analyzed. Perceptions of dentofacial esthetics by laypersons as well as health-care professionals such as orthodontists and/ or general dental practitioners (GDP) need to be considered during orthodontic treatment planning. ${ }^{[4]}$ The impact of gingival displays on the perception of smile esthetics is well documented in the literature and suggests that orthodontists tend to be more critical than laypersons when dental disharmony is small. A small gingival margin discrepancy of $2 \mathrm{~mm}$ between the central and lateral incisors was not considered unaesthetic by laypersons or dental professionals. ${ }^{[5,6]}$ On the other hand, it has been suggested that the maxillary central incisors and canines should be positioned at approximately same level, with incisal edge of the lateral incisors positioned 1-1.5 mm higher. ${ }^{[5,7-9]}$ However, the esthetic impact of variations in the vertical position of the maxillary lateral incisor still remains unclear. ${ }^{[10]}$

Recent studies have highlighted another important factor that enhances smile attractiveness and creates a harmonious proportion when applied to the maxillary teeth. ${ }^{[2,11]}$ The golden proportion requires a $62 \%$ reduction in the viewing width of each tooth, beginning with, and proceeding posterior from the central incisor. ${ }^{[12,13]}$ This principle is ideally used to determine the width of the teeth as they relate to each other. However, there are many important design considerations that need to be clarified before the application of golden proportion. The golden proportion can be applied only after the incisal edge position, incisal plane, gingival plane, and central incisor length have been determined. ${ }^{[14-16]}$

The purpose of the present study was to determine the perception of smile esthetics among dental health-care professionals and laypersons, with respect to different levels of maxillary lateral incisors. The study also highlights the importance of creating a harmonious golden proportion when restoring or replacing the lateral incisors.

\section{MATERIALS AND METHODS}

A photograph of a female patient was taken while smiling displaying the lips and teeth only. The photograph was taken using a Nikon D750 DSLR full frame Full frame 24.3 megapixel CMOS image sensor and EXPEED 4 image processor. (Nikon Corp. Japan) with a $10 \mathrm{~mm}$ macro lens (Tokina Co.). Sigma Flash ring EM 140-DG. A Sb-r200 twin flash system (Nikon Corp. Japan) was attached using an adjustable scorpion medical bracket (Agno's Tech Engineering Co.). The camera was set up by selecting the following options: ISO 100, $100 \mathrm{~mm}, \mathrm{f} / 45$, and $1 / 60 \mathrm{~s}$ exposure time. The photograph was taken at the same height as that of the subject and from a distance of $0.5 \mathrm{~m}$. Many photographs were taken and the final photograph used in this study was selected by the authors, using three criteria. The photograph that was closest to natural view, well positioned, and taken under best lighting conditions was selected for the study.

The photograph was later manipulated digitally with Adobe ${ }^{\circledR}$ Photoshop ${ }^{\circledR}$ CS6 photo-editing software (Adobe Systems Inc., San Jose, CA, USA). The lasso tool on photoshop was used to alter the dimensions of the maxillary lateral incisor producing three sets of photographs each containing five photographs. The width of the lateral incisor in relation to the central incisor was altered following the rule of golden proportion at $5 \%$ intervals, from $52 \%$ to $72 \%$, to produce a set of five pictures, shown in Figure 1. In the second set, the length of the lateral incisor in relation to the central incisor was altered at $0.5 \mathrm{~mm}$ increments, 0 to $-2 \mathrm{~mm}$, to produce five different incisal levels, as shown in Figure 2 (a-e). In the third set, the gingival height of the lateral incisors in relation to the central incisor was altered at $0.5 \mathrm{~mm}$ increments, to produce five gingival heights, ranging from 0 to $-2 \mathrm{~mm}$, as shown in Figure 3 (ae). The photographs were then printed on a 4 " $\times$ 6 " paper with a matt finish. Each photograph was then assigned a unique identification code which was written on the back of the picture, for use while collecting the results.

The images were randomized and rated for attractiveness by 150 participants, divided into three equal groups, each consisting of 25 male and 25 female participants: (A) 50 orthodontists, (B) 50 GDPs, and (C) 50 laypersons. The photographs were divided into three groups, each containing five images. The participants were asked to give a rank score to the images from the most attractive to the least attractive for each group separately. Each participant was interviewed separately and was given $10 \mathrm{~s}$ for each image, with an additional $30 \mathrm{~s}$ to verify their 


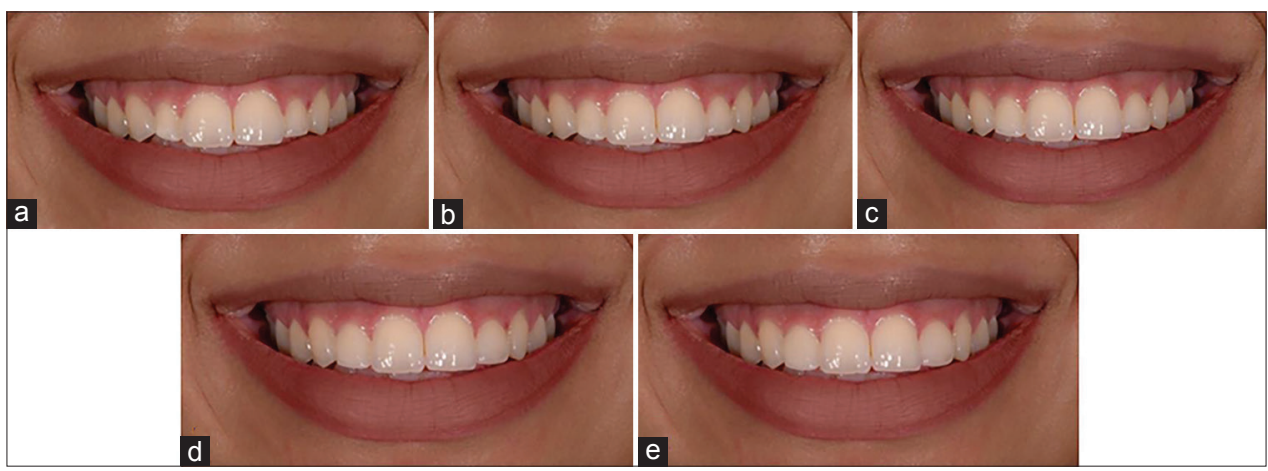

Figure 1: Full smile views after alteration of lateral incisor golden proportion by $5 \%$ increments: (a) $52 \%$, (b) $57 \%$, (c) $62 \%$ (unaltered), (d) $67 \%$, and (e) $72 \%$

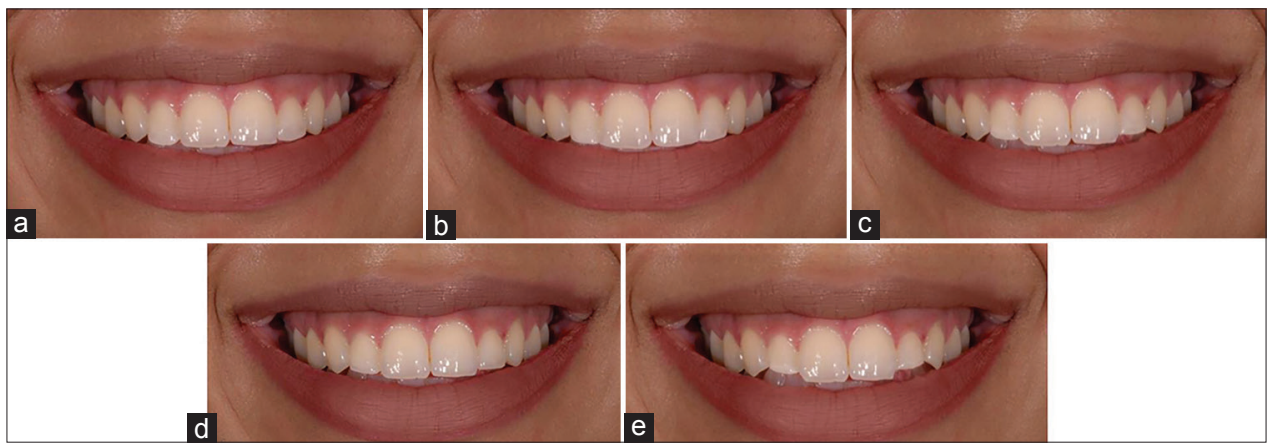

Figure 2: Full smile views after alteration of lateral incisor incisal length in $0.5 \mathrm{~mm}$ steps: (a) $-0.5 \mathrm{~mm}$, (b) 0 (unaltered), (c) $-1.5 \mathrm{~mm}$, (d) $-1 \mathrm{~mm},(\mathrm{e})-2 \mathrm{~mm}$

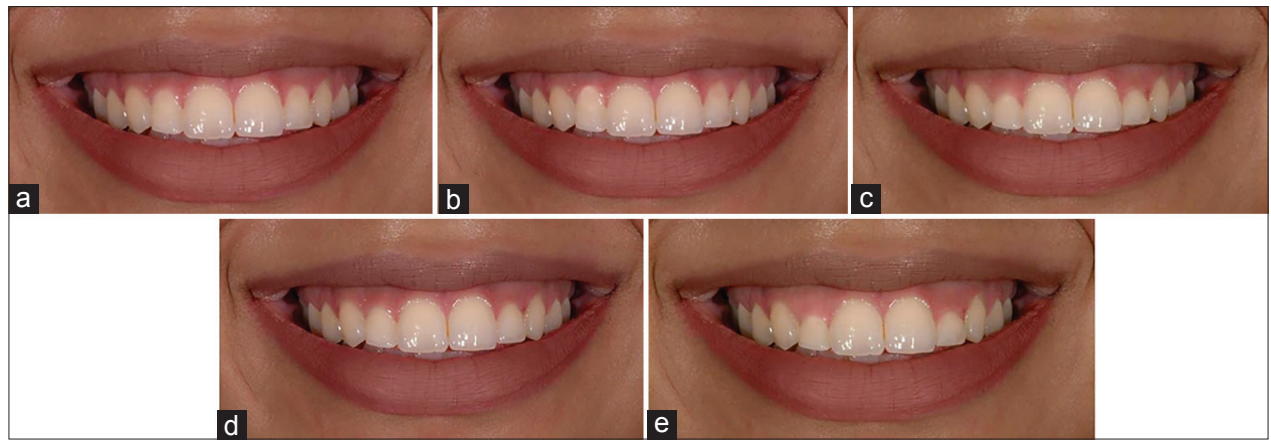

Figure 3: Full smile views after alteration of lateral incisor gingival height in $0.5 \mathrm{~mm}$ steps:(a) $-0.5 \mathrm{~mm}$, (b) 0 (unaltered), (c) $-1.5 \mathrm{~mm},(\mathrm{~d})-1 \mathrm{~mm},(\mathrm{e})-2 \mathrm{~mm}$

choices at the end of the interview. The participants were instructed to organize the images until they have achieved a final rank order within the given time and disregard the code at the back of each picture.

\section{Statistical analysis}

The data collected were subjected to descriptive statistical analysis. Mann-Whitney U-test was used to analyze the pair-wise differences in the mean scores between groups, whereas Kruskal-Wallis H-test and cross-tabulation were used to determine the significant difference within all the participants in the study. The $P$ value was calculated using Chi-square test and the statistical significance was set $<0.05$ (95\% confidence interval).

\section{RESULTS}

The participants were divided according to their profession and a total of fifty orthodontists, fifty GDPs, and fifty laypersons were engaged in this study. The orthodontists and GDPs had an average experience of $7.50 \pm 3.49$ and $7.14 \pm 2.85$ years, respectively. The mean \pm standard deviation age of orthodontists, GDP, and laypersons was $36.88 \pm 3.79,33.36 \pm 3.62$, and 28.8 \pm 2.97 years, respectively, as depicted in Tables 1 and 2 .

There was no significant difference between males and females for all participants of the study, in judging the level of attractiveness of lateral incisor on smile design. Therefore, the data from the three groups 
were pooled for cross-tabulations, Kruskal-Wallis, and Mann-Whitney analyses. While comparing the perceptions of orthodontists with the other two groups, there was a statistically significant difference in most of the situations. A reasonable number of orthodontists (38\%) believed that 72\% lateral-to-central incisor width proportion is not attractive compared to $20 \%$ of laypersons with the same score. On the other hand, few orthodontists (4\%) showed a high score for $72 \%$ lateral-to-central incisor width proportion compared to $30 \%$ of laypersons who found such a width to be highly attractive $(P<0.021)$.

\begin{tabular}{lc}
\multicolumn{2}{l}{ Table 1: Overall demographic distribution } \\
\hline Parameter & Value (years) \\
\hline Age & $33.01 \pm 4.79$ \\
Mean $\pm S D$ & 33 \\
Median & \\
Experience & $7.32 \pm 3.18$ \\
Mean \pm SD & 7.5 \\
Median &
\end{tabular}

Statistical significance of difference in the rating of the ideal golden proportion (62\%) among all the participants was also investigated in the present study. Two-fifths of orthodontists (42\%) believed that $62 \%$ golden proportion is the most attractive, whereas only $10 \%$ of the laypersons and $24 \%$ of GDPs were in agreement $(P<0.001)$ as shown in Table 3 . The $0 \mathrm{~mm}$ gingival level was considered acceptable to one-third of the orthodontists (33.3\%) and only one-fifth of the GDPs (18\%) ranked it as attractive. In general, all of the groups had similar ranking of the least attractive gingival level is $-2 \mathrm{~mm}$, with the highest percentage of GDPs (76\%), followed by orthodontists $(60 \%)$ and then laypersons $(58 \%)$. Almost one-fourth (24\%) of the orthodontists and laypersons agreed that $-1.5 \mathrm{~mm}$ gingival height is not attractive, whereas more than half of the GDPs (56\%) had same opinion. However, one-fifth $(22 \%)$ of the orthodontists ranked it as attractive with score of 4 compared to only $4 \%$ of GDPs and $10 \%$ of laypersons gave the same ranking $(P<0.023)$.

\begin{tabular}{|c|c|c|c|}
\hline Parameter & Laypersons $(n=50)$ & GDPs $(n=50)$ & Orthodontists $(n=50)$ \\
\hline \multicolumn{4}{|l|}{ Age (years) } \\
\hline Mean $\pm S D$ & $28.8 \pm 2.97$ & $33.36 \pm 3.62$ & $36.88 \pm 3.79$ \\
\hline Median & 28 & 33.5 & 37 \\
\hline \multicolumn{4}{|c|}{ Experience (years) } \\
\hline Mean $\pm S D$ & - & $7.14 \pm 2.85$ & $7.5 \pm 3.49$ \\
\hline Median & - & 7.5 & 7.5 \\
\hline
\end{tabular}

\begin{tabular}{|c|c|c|c|c|}
\hline Parameter & Laypersons $(n=50)$ & GDPs $(n=50)$ & Orthodontists $(n=50)$ & $P$ \\
\hline \multicolumn{5}{|c|}{ Golden proportion (\%) } \\
\hline 52 & $1.86 \pm 1.16$ & $2.06 \pm 1.17$ & $1.86 \pm 0.97$ & 0.537 \\
\hline 57 & $3.04 \pm 1.26$ & $2.84 \pm 1.15$ & $2.74 \pm 1.26$ & 0.581 \\
\hline 62 & $3.24 \pm 1.19$ & $3.56 \pm 1.23$ & $4.02 \pm 1.13$ & 0.001 \\
\hline 67 & $3.78 \pm 1.22$ & $3.76 \pm 1.25$ & $4.02 \pm 1.10$ & 0.535 \\
\hline 72 & $3.08 \pm 1.54$ & $2.78 \pm 1.59$ & $2.36 \pm 1.12$ & 0.078 \\
\hline \multicolumn{5}{|c|}{ Gingival height $(\mathrm{mm})$} \\
\hline 0 & $3.08 \pm 1.24$ & $3.48 \pm 1.33$ & $2.80 \pm 1.55$ & 0.054 \\
\hline-0.5 & $3.90 \pm 1.20$ & $3.96 \pm 1.12$ & $3.50 \pm 1.33$ & 0.165 \\
\hline-1 & $3.96 \pm 1.09$ & $3.80 \pm 0.97$ & $4.16 \pm 0.87$ & 0.166 \\
\hline-1.5 & $2.26 \pm 0.88$ & $2.40 \pm 0.86$ & $2.78 \pm 0.95$ & 0.023 \\
\hline-2 & $1.80 \pm 1.21$ & $1.38 \pm 0.83$ & $1.76 \pm 1.04$ & 0.082 \\
\hline \multicolumn{5}{|c|}{ Incisal length (mm) } \\
\hline 0 & $3.86 \pm 1.16$ & $3.38 \pm 1.32$ & $2.88 \pm 1.33$ & 0.001 \\
\hline-0.5 & $3.96 \pm 1.18$ & $3.50 \pm 1.25$ & $3.38 \pm 0.94$ & 0.008 \\
\hline-1 & $3.10 \pm 0.93$ & $3.92 \pm 1.10$ & $4.42 \pm 0.88$ & 0.000 \\
\hline-1.5 & $2.74 \pm 1.09$ & $2.78 \pm 1.11$ & $2.82 \pm 1.24$ & 0.953 \\
\hline-2 & $1.34 \pm 0.92$ & $1.42 \pm 0.76$ & $1.50 \pm 0.81$ & 0.148 \\
\hline
\end{tabular}


In case of lateral incisal length correction, the $-1 \mathrm{~mm}$ [Figure 2d] was considered the most attractive to orthodontists (64\%) and GDPs (40\%), whereas only $6 \%$ of laypersons found it attractive. This was followed by $-0.5 \mathrm{~mm}$ incisal length, as the second most attractive to dental health-care professionals and most attractive to laypersons $(40 \%)$. On the other hand, $-2 \mathrm{~mm}$ incisal length was rated as the least attractive by all the participants (pooled data). According to the GDPs and layperson's standpoint, $0 \mathrm{~mm}$ incisal length was acceptable, whereas $40 \%$ of the orthodontists ranked it as highly unattractive $(P<0.001)$.

Pair-wise Mann-Whitney analysis was conducted and a statistically significant difference between orthodontists and laypersons in ranking the level of attractiveness of lateral incisal length was found $(P<0.001)$, as shown in Table 4.

\section{DISCUSSION}

In the highly competitive society, we live in these days, a pleasing appearance may mean the difference between success and failure in both our personal and professional life.

Smile analysis and smile design are very important in orthodontic diagnosis and treatment planning, ${ }^{[17]}$ people have become more critical of their smiles, and with such refined esthetic expectations, demand for dental treatment has been shifted from function to esthetics. ${ }^{[10,18]}$ To provide the highest level of dental care, dentists are required to place just as much emphasis on esthetics as they would on function and dental health when planning treatment. Several studies have assessed smile esthetics to attempt to objectivity define the guidelines of anterior dental esthetics. ${ }^{[10-12,19]}$ Few have focused on the influence of maxillary lateral incisor proportions and relation to adjacent teeth on the perception of anterior smile esthetics. The aim of this study was to shed light on the importance of the maxillary lateral incisor and its effect on anterior smile esthetics, an important focus of a treatment plan.

It is worth emphasizing that the degrees of deviation from the norms chosen in this study are based on acceptable amounts of deviation proposed by previous studies, and it was expected that the smile containing deviation from the norms would receive significantly lower scores. ${ }^{[12]}$ Many studies have shown different threshold levels, among dentists and laypersons, in detecting changes of smile traits. In most situations, orthodontists were more critical in their evaluation. However, for the most attractive smiles, the participating groups did not display statistically significant differences. Accordingly, it can be hypothesized that an ideal smile arrangement can easily be recognized by any group of raters. However, when smaller deviations are included, a difference in judgment appears. ${ }^{[13-15]}$ In the present study, two groups of dental care professionals were included

\begin{tabular}{|c|c|c|c|}
\hline \multirow[t]{2}{*}{ Parameter } & \multicolumn{3}{|c|}{$P$} \\
\hline & Orthodontists versus GDPs & Orthodontists versus lay people & GDPs versus lay people \\
\hline \multicolumn{4}{|c|}{ Golden proportion (\%) } \\
\hline 52 & 0.482 & 0.654 & 0.281 \\
\hline 57 & 0.722 & 0.303 & 0.508 \\
\hline 62 & 0.034 & 0.000 & 0.148 \\
\hline 67 & 0.332 & 0.332 & 0.986 \\
\hline 72 & 0.305 & 0.021 & 0.250 \\
\hline \multicolumn{4}{|c|}{ Gingival height (mm) } \\
\hline 0 & 0.028 & 0.327 & 0.082 \\
\hline-0.5 & 0.079 & 0.135 & 0.838 \\
\hline-1 & 0.049 & 0.440 & 0.331 \\
\hline-1.5 & 0.045 & 0.010 & 0.465 \\
\hline-2 & 0.049 & 0.969 & 0.045 \\
\hline \multicolumn{4}{|c|}{ Incisal length (mm) } \\
\hline 0 & 0.065 & 0.000 & 0.068 \\
\hline-0.5 & 0.427 & 0.002 & 0.047 \\
\hline-1 & 0.013 & 0.000 & 0.000 \\
\hline-1.5 & 0.954 & 0.803 & 0.774 \\
\hline-2 & 0.449 & 0.046 & 0.258 \\
\hline
\end{tabular}


as previous studies have shown that they are more accurate in detecting deviations from ideal norms. The third group of laypersons was chosen because they are the primary consumers of dental treatment.

An interesting aspect to be discussed is the idea of golden proportion, a guideline suggesting that the size of the smaller subject is $62 \%$ of the larger subject when viewed from a frontal view. Lombardi stated that a maxillary lateral incisor that is $62 \%$ of the width of the maxillary central incisor is ideal. ${ }^{[11]}$ In the present smile analysis, the most attractive smile was the one, in which the lateral incisor width was $67 \%$ of the width of the central incisor [Figure 1d], as rated by $44 \%$ of orthodontists, $39 \%$ of GDPs, and 36\% of laypersons. These results are similar to those of Bukharyet al. ${ }^{[10]}$ Golden proportion of $62 \%$ was found to be the most attractive by $42 \%$ of orthodontists, even though a small group of laypersons and GDPs found it to be highly attractive. Unlike other studies, Ker et al..$^{[6]}$ have surveyed 243 laypersons using a slider bar where the width of the maxillary lateral incisor was altered in $0.18 \mathrm{~mm}$ increments. The evaluators found that a lateral incisor width that is $72 \%$ the width of the central incisor to be ideal, and widths of the lateral incisor ranging from $53 \%$ to $76 \%$ the width of the maxillary central incisors, was found acceptable. ${ }^{[6]}$ In fact, these exact proportions rarely occur in the natural dentition, and wider lateral incisors might be needed to establish a good anterior guidance from an orthodontist's point of view. Golden proportion is just one of the many factors involved in smile design. The value of the golden proportion is a diagnostic tool in evaluating a smile, and as a guide to veneer preparation and fabrication.

In the current study, awareness about the most attractive lateral incisal length between orthodontists, GDPs, and laypersons was investigated, and according to the attractiveness scale, $-1 \mathrm{~mm}$ length was considered the most appealing smile to orthodontists $(64 \%)$ and GDPs $(40 \%)$ but not to laypersons $(6 \%)$ who preferred the $-0.5 \mathrm{~mm}$ incisal length. It is not surprising to find that dentists were significantly more reliable than nonhealth-care professional participants. One possibility as to why reliability of the dentists was significantly higher is that the nonmedical group was less sensitive to changes in length compared to width. This agrees with the findings of Kokich et al., who reflect that laypeople were less perceptive to crown length discrepancy than dental professionals. ${ }^{[10,12]}$
In the present study, the most appealing smile for orthodontists and laypersons exhibited $-0.5 \mathrm{~mm}$ wear on the lateral incisor ${ }^{[8]}$ Bukhary et al. found that a maxillary lateral incisor position that was $1-1.5 \mathrm{~mm}$ shorter than the central incisor was the most accepted. ${ }^{[10]}$ King et al. evaluated the ideal vertical position of maxillary lateral incisor by orthodontists, general dentists, and laypeople and set it as about $0.5 \mathrm{~mm}$ above the incisal plane. ${ }^{[20]}$ All of these results suggest that treatment of minor vertical position discrepancies might reflect an exaggerated concern by dental care professionals rather than an esthetic demand of the patients. ${ }^{[5,10]}$

Both orthodontics (40\%) and laypersons (42\%) agreed that the most attractive gingival display on smile design is at $-1 \mathrm{~mm}$, whereas GDPs (46\%) decided that $-0.5 \mathrm{~mm}$ as the most attractive. The latter observation is consistent with the findings of Springer et al., ${ }^{[4,6]}$ in which laypeople concluded that the most appealing gingival display to be almost $-0.5 \mathrm{~mm}$.

Further research on these dental design parameters and their specific hierarchy of influence on smile esthetics is recommended to enhance their utility in esthetic dentistry.

\section{CONCLUSIONS}

1. Golden proportion of $62 \%$ and $67 \%$ were ranked the highest by orthodontists, whereas GDPs and laypersons preferred $67 \%$

2. Orthodontist and laypersons agreed on a lateral incisor gingival height of $-1 \mathrm{~mm}$ to be more attractive whereas GDP preferred a gingival height of $-0.5 \mathrm{~mm}$

3. A $-0.5 \mathrm{~mm}$ lateral incisor length received the highest score by laypersons, in contrast to orthodontists and GDPs who agreed that the most attractive incisal length is $-1 \mathrm{~mm}$.

\section{Financial support and sponsorship Nil.}

\section{Conflicts of interest}

There are no conflicts of interest.

\section{REFERENCES}

1. Shahid F, Alam MK, Khamis MF. Maxillary and mandibular anterior crown width/height ratio and its relation to various arch perimeters, arch length, and arch width groups. Eur J Dent 2015;9:490-9.

2. Rosenstiel SF, Ward DH, Rashid RG. Dentists' preferences of anterior tooth proportion - A web-based study. J Prosthodont 2000;9:123-36.

3. Soh J, Chew MT, Chan YH. Perceptions of dental esthetics of Asian 


\section{Al Taki, et al.: Impact of lateral incisor dimension variations on esthetics}

orthodontists and laypersons. Am J OrthodDentofacialOrthop 2006;130:170-6.

4. Springer NC, Chang C, Fields HW, Beck FM, Firestone AR, Rosenstiel S, et al. Smile esthetics from the layperson's perspective. Am J OrthodDentofacialOrthop 2011;139:e91-101.

5. Raj V. Esthetic paradigms in the interdisciplinary management of maxillary anterior dentition-A review. J EsthetRestor Dent 2013;25:295-304.

6. Ker AJ, Chan R, Fields HW, Beck M, Rosenstiel S. Esthetics and smile characteristics from the layperson's perspective: A computer-based survey study. J Am Dent Assoc 2008;139:1318-27.

7. Eslami N, Omidkhoda M, Shafaee H, Mozhdehifard M. Comparison of esthetics perception and satisfaction of facial profile among male adolescents and adults with different profiles. J OrthodSci 2016;5:47-51.

8. Caramello F, Bittencourt MA, Machado AW. Influence of maxillary incisor level of exposure on the perception of dentofacial aesthetics among orthodontists and laypersons. J World FedOrthod 2015;4:108-13.

9. Machado AW, McComb RW, Moon W, Gandini LG Jr. Influence of the vertical position of maxillary central incisors on the perception of smile esthetics among orthodontists and laypersons. J EsthetRestor Dent 2013;25:392-401.

10. Bukhary SM, Gill DS, Tredwin CJ, Moles DR. The influence of varying maxillary lateral incisor dimensions on perceived smile aesthetics. $\mathrm{Br}$ Dent J 2007;203:687-93.

11. Lombardi RE. The principles of visual perception and their clinical application to denture esthetics. J Prosthet Dent 1973;29:358-82.

12. Kokich VO Jr., Kiyak HA, Shapiro PA. Comparing the perception of dentists and lay people to altered dental esthetics. J Esthet Dent 1999;11:311-24.

13. Kokich V. Esthetics and anterior tooth position: An orthodontic perspective. part I: Crown length. J EsthetRestor Dent 1993;5:519-23.

14. Johnston CD, Burden DJ, Stevenson MR. The influence of dental to facial midline discrepancies on dental attractiveness ratings. Eur J Orthod 1999;21:517-22.

15. Shaw WC, Lewis HG, Robertson NR. Perception of malocclusion. Br Dent J 1975;138:211-6.

16. Machado AW, Moon W, Gandini LG Jr. Influence of maxillary incisor edge asymmetries on the perception of smile esthetics among orthodontists and laypersons. Am J OrthodDentofacialOrthop 2013;143:658-64.

17. Abraham A, George J, Peter E, Philip K, Chankramath R, Johns DA, et al. Establishment of a new relationship between posed smile width and lower facial height: A cross-sectional study. Eur J Dent 2015;9:394-9.

18. Alsulaimani FF, Batwa W. Incisors' proportions in smile esthetics. J OrthodSci 2013;2:109-12.

19. Sarver DM, Ackerman MB. Dynamic smile visualization and quantification: Part 2. Smile analysis and treatment strategies. Am J OrthodDentofacialOrthop 2003;124:116-27.

20. King KL, Evans CA, Viana G, BeGole E, Obrez A. Preferences for vertical position of the maxillary lateral incisors. World J Orthod 2008;9:147-54. 